\title{
Transcriptomic analysis reveals the molecular mechanisms of rumen wall morphological and functional development induced by different solid diet introduction in a lamb model
}

Daming Sun ${ }^{1,2,3}$, Yuyang Yin ${ }^{4}$, Changzheng Guo ${ }^{1,2,3}$, Lixiang Liu ${ }^{1,2,3}$, Shengyong Mao ${ }^{1,2,3}$, Weiyun Zhu ${ }^{1,2,3}$ and Junhua Liu ${ }^{1,2,3^{*}}$

\begin{abstract}
Background: This study aimed to elucidate the molecular mechanisms of solid diet introduction initiating the cellular growth and maturation of rumen tissues and characterize the shared and unique biological processes upon different solid diet regimes.

Methods: Twenty-four Hu lambs were randomly allocated to three groups fed following diets: goat milk powder only $(\mathrm{M}, n=8)$, goat milk powder + alfalfa hay $(\mathrm{MH}, n=8)$, and goat milk powder + concentrate starter $(\mathrm{MC}, n=8)$. At 42 days of age, the lambs were slaughtered. Ruminal fluid sample was collected for analysis of concentration of volatile fatty acid (VFA) and microbial crude protein (MCP). The sample of the rumen wall from the ventral sac was collected for analysis of rumen papilla morphology and transcriptomics.
\end{abstract}

Results: Compared with the M group, MH and MC group had a higher concentration of VFA, MCP, rumen weight, and rumen papilla area. The transcriptomic results of rumen wall showed that there were 312 shared differentially expressed genes (DEGs) between in "MH vs. M" and "MC vs. M", and 232 or 796 unique DEGs observed in "MH vs. M" or "MC vs. M", respectively. The shared DEGs were most enriched in VFA absorption and metabolism, such as peroxisome proliferator-activated receptor (PPAR) signaling pathway, butanoate metabolism, and synthesis and degradation of ketone bodies. Additionally, a weighted gene co-expression network analysis identified M16 (2,052 genes) and M18 (579 genes) modules were positively correlated with VFA and rumen wall morphology. The M16 module was mainly related to metabolism pathway, while the M18 module was mainly associated with signaling transport. Moreover, hay specifically depressed expression of genes involved in cytokine production, immune (Continued on next page)

\footnotetext{
* Correspondence: liujunhua0011@163.com

'Jiangsu Key Laboratory of Gastrointestinal Nutrition and Animal Health, Laboratory of Gastrointestinal Microbiology, College of Animal Science and Technology, Nanjing Agricultural University, Nanjing 210095, Jiangsu Province, China

${ }^{2}$ National Center for International Research on Animal Gut Nutrition, Nanjing Agricultural University, Nanjing 210095, China

Full list of author information is available at the end of the article
}

(c) The Author(s). 2021 Open Access This article is licensed under a Creative Commons Attribution 4.0 International License, which permits use, sharing, adaptation, distribution and reproduction in any medium or format, as long as you give appropriate credit to the original author(s) and the source, provide a link to the Creative Commons licence, and indicate if changes were made. The images or other third party material in this article are included in the article's Creative Commons licence, unless indicated otherwise in a credit line to the material. If material is not included in the article's Creative Commons licence and your intended use is not permitted by statutory regulation or exceeds the permitted use, you will need to obtain permission directly from the copyright holder. To view a copy of this licence, visit http://creativecommons.org/licenses/by/4.0/ The Creative Commons Public Domain Dedication waiver (http://creativecommons.org/publicdomain/zero/1.0/) applies to the data made available in this article, unless otherwise stated in a credit line to the data. 
(Continued from previous page)

response, and immunocyte activation, and concentrate starter mainly altered nutrient transport and metabolism, especially ion transport, amino acid, and fatty acid metabolism.

Conclusions: The energy production during VFA metabolism may drive the rumen wall development directly. The hay introduction facilitated establishment of immune function, while the concentrate starter enhanced nutrient transport and metabolism, which are important biological processes required for rumen development.

Keywords: Concentrate, Hay, Lamb, Rumen development, Transcriptome

\section{Background}

Rumen, as the specific digestive and metabolism organ in ruminants, is responsible for feed degradation, nutrient absorption and metabolism, and immune response, where microbial fermentation produces volatile fatty acids (VFAs), microbial proteins, vitamins, and other nutrients $[1,2]$. Volatile fatty acids in the rumen contribute up to $70 \%$ energy requirements of the host [3], and microbial proteins account for up to $90 \%$ of amino acids utilized for host protein synthesis [4]. Therefore, a welldeveloped rumen is critical for ruminant health and performance. Rumen development process consists of microbial colonization, functional achievement, as well as anatomic development [5]. Microbial colonization performs efficient digestion of feed components, thereby providing nutrients for the physiological requirements of the animal [5]. Rumen wall mainly functions as efficient absorption and metabolism of VFA, maintains rumen homeostasis, and provides energy to host [6]. In addition, rumen wall has an important role in immune and barrier functions, thus, its integrity is essential to ensure the health of ruminants [1]. The transition phase (pre-ruminant) of the young ruminant is the sensitive window time to manipulate rumen wall development. Thus, improving rumen wall morphology and physiological function development by nutritional strategies during this early period has great significance for ruminant life-time health and production.

In newborn ruminants, suckling liquid feed (milk or milk replacer) mainly flows into the abomasum through the esophageal groove, resulting in less fermentation substrate stimulating rumen development [7, 8]. Hay and concentrate starter are the main diet components for improving rumen wall morphological development in calves and lambs' production. Previous studies showed that concentrate starter introduction had larger emptied rumen weight and papilla surface than hay in pre-weaned calf, and hay introduction especially increased the volume of the rumen [9-11]. However, the molecular mechanism of rumen wall morphological and functional development is not well understood. At the molecular level, a previous study indicated that, compared with concentrate starter, hay plus concentrate starter introduction enhanced expression of genes related to VFA absorption in the ruminal epithelia of calves [12]. Our recent study showed that, compared with hay introduction, hay plus concentrate starter introduction increased expression of genes associated with cell proliferation, while decreased the expression of genes related to VFA absorption [11]. This indicated that hay and concentrate may have their own unique effects on the molecular processes of rumen morphological and functional development in pre-weaning ruminants. By transcriptomics technology, emerging evidence has shown that hay feeding activated gene pathways participating in energy production [13], and hay plus concentrate starter introduction enhanced amino acid and fatty acid metabolic processes in the rumen tissue of lambs during pre-weaning period [14]. Compared to calves fed with only milk replacer before 42 days of age, calves with concentrate introduction from 42 to 56 days of age activated molecular pathways primarily related to the cell cycle in the rumen wall [13]. Also, hay plus concentrate starter introduction activated gene pathways participating in growth and development in the rumen epithelium of lambs [15]. These studies indicated that hay or concentrate starter introduction may affect specific molecular and biological processes in the morphological and functional development of rumen wall. However, these studies mixed the age and diet factors, so that it is not confirmed that these changes are mainly derived from hay or concentrate introduction. Furthermore, it is unclear how hay or concentrate starter introduction drives differently morphological and functional development in the rumen wall of young ruminants.

This study aimed to investigate the molecular mechanisms of rumen wall morphological and functional development induced by different solid diet introduction, and to characterize the specific molecular and biological processes upon introduction of hay or concentrate.

\section{Methods}

\section{Animal experiment design}

The experimental design and procedures were approved by the Animal Care and Use Committee of Nanjing Agricultural University. Twenty-four 12-day-old $\mathrm{Hu}$ lambs (12 males and 12 females) were separated from their dams and fed mixed goat milk powder (water: goat milk 
powder $=10: 1)$ in individual pens. At 15 days of age, the lambs were randomly assigned by sex to three groups fed following diets: goat milk powder only (M, $n=8)$, goat milk powder + alfalfa hay ( $\mathrm{MH}, n=8)$, and goat milk powder + concentrate starter $(\mathrm{MC}, n=8)$. The lambs in the $\mathrm{M}$ group had access to mixed goat milk powder $(23.85 \%$ crud protein, $25.30 \%$ fat, and $36.30 \%$ lactose) for $1 \mathrm{~h}$ at each feeding time. The feeding amount of milk powder per lamb in $\mathrm{MH}$ and $\mathrm{MC}$ group $(600 \mathrm{~mL} / \mathrm{d})$ was provided according to previous research, which was equal to $10 \%$ of their initial average body weight (BW, about $6 \mathrm{~kg})[10,16]$ and could freely get access to alfalfa hay or concentrate starter, respectively. All the lambs were fed mixed goat milk four times a day (07:00, 12:00, 17:00, and 22:00) and had ad libitum access to water. Lambs in $\mathrm{MH}$ and MC group were fed with $200 \mathrm{~g} / \mathrm{d}$ of solid diet during the first 2 weeks, followed by $500 \mathrm{~g} / \mathrm{d}$ during the next 2 weeks. The solid diet was offered in equal amounts at 08:00 and 17:00 daily. The dry matter intake of diet was recorded every day. Nutritional levels of alfalfa and concentrate starter are shown in Table 1.

\section{Sample collection}

At 42 days of age, the jugular vein blood of lambs was collected using a blood collection tube containing 40 $\mathrm{KIU}$ Na-heparin/mL blood at 2 to $4 \mathrm{~h}$ after the last diet feeding. Plasma was harvested by centrifuging the blood samples at $3,000 \mathrm{r} / \mathrm{min}$ at $4{ }^{\circ} \mathrm{C}$ for $10 \mathrm{~min}$ and stored at $-20^{\circ} \mathrm{C}$. Then, lambs were stunned by electric shock and killed by exsanguinations. Immediately after slaughter, rumen was opened by an incision along the dorsal curvature. All rumen content was mixed for determining the $\mathrm{pH}$ value and then was strained through four layers of cheesecloth for sampling ruminal fluid. The ruminal fluid samples were stored at $-20^{\circ} \mathrm{C}$ until analysis for the concentrations of VFAs, ammonia nitrogen $\left(\mathrm{NH}_{3}-\mathrm{N}\right)$, and microbial crude protein $(\mathrm{MCP})$. After recording the weight and volume of the rumen, rumen wall $(3 \mathrm{~cm} \times 3 \mathrm{~cm})$ sample from the ventral sac was collected for analysis of rumen papilla morphology, histomorphometry microscopy, and transcriptomics as described previously $[11,14,15]$.

\section{Physiological parameter measurements}

Ruminal $\mathrm{pH}$ and VFA concentration were detected by portable $\mathrm{pH}$ meter (HI 9024C; HANNA Instruments, Woonsocket, RI, USA) and capillary column gas chromatography (GC-14B; Shimadzu, Tokyo, Japan), respectively. The concentrations of $\mathrm{NH}_{3}-\mathrm{N}$ [17] and MCP [18] were analyzed according to previous studies. Rumen volume [19], morphometric and histomorphometric microscopy of the rumen wall $[10,20]$ were examined as previously described. The plasma concentrations of insulin-like growth factor $1, \quad \beta$-hydroxybutyric acid
Table 1 Ingredient and chemical composition of the diets for alfalfa hay group $(\mathrm{MH})$ and concentrate starter group (MC) lambs (dry matter basis)

\begin{tabular}{lll}
\hline Item & MH & MC \\
\hline Ingredients, \% DM & 98.50 & 0.00 \\
Alfalfa hay & 0.00 & 56.00 \\
Corn & 0.00 & 31.00 \\
Soybean meal & 0.00 & 4.00 \\
Wheat & 0.00 & 5.00 \\
Whey powder & 0.00 & 1.00 \\
limestone meal powder & 0.00 & 1.50 \\
Calcium monophosphate & 0.50 & 0.50 \\
Nacl & 1.00 & 1.00 \\
Premix & \\
Nutrient composition & & \\
Metabolic energy, MJ/kg DM ${ }^{b}$ & 8.03 & 12.67 \\
Crude protein, \% DM & 18.76 & 19.62 \\
Ether extract, \% DM & 2.26 & 3.68 \\
Crude fiber, \% DM & 22.29 & 3.35 \\
Crude ash, \% DM & 7.46 & 3.16 \\
NDF, \% DM & 36.45 & 10.23 \\
ADF, \% DM & 30.54 & 5.11 \\
Starch, \% DM & 1.00 & 35.64 \\
Ca, \% DM & 1.38 & 1.04 \\
P, \% DM & 0.50 & 0.50 \\
\hline Con & & \\
\hline
\end{tabular}

${ }^{a}$ Contained $102 \mathrm{~g} / \mathrm{kg}$ of $\mathrm{Zn}, 47 \mathrm{~g} / \mathrm{kg}$ of Mn, $26 \mathrm{~g} / \mathrm{kg}$ of $\mathrm{Cu}, 1140 \mathrm{mg} / \mathrm{kg}$ of I, 500 $\mathrm{mg} / \mathrm{kg}$ of Se, $340 \mathrm{mg} / \mathrm{kg}$ of Co, 17,167,380 IU/kg of vitamin A, 858,370 IU/ $/ \mathrm{kg}$ of vitamin $\mathrm{D}$, and $23,605 \mathrm{IU} / \mathrm{kg}$ of vitamin $\mathrm{E}$

${ }^{b}$ Calculated based on Ministry of Agriculture of China recommendations (MOA, 2004). DM, dry matter

(BHBA), insulin, and glucose were analyzed by the commercial kits (Jiancheng Bioengineering Institute, Nanjing) following the manufacturer's protocols.

\section{RNA extraction and sequencing}

Four rumen tissue samples per group were randomly selected to conduct transcriptome analysis. Total RNA of rumen tissues sample was isolated by TRIzol (Invitrogen Life Technologies, Carlsbad, CA, USA), and RNA concentrations and quality were examined by NanoDrop (NanoDrop Technologies, Wilmington, DE, USA). A total amount of $1.5 \mu \mathrm{g}$ RNA per sample was used for cDNA library construction [21]. The ribosomal RNA was removed from total RNA using the Ribo-Zero ${ }^{\text {Tw }}$ Kit (Epicentre, Madison, WI, USA). Then, sequencing libraries were generated using NEBNext ${ }^{\circ}$ Ultra $^{\mathrm{Tm}}$ Directional RNA Library Prep Kit for Illumina (NEB, USA) following manufacturer's recommendations, and index codes were added to attribute sequences to each sample. The clustering of the index-coded samples was performed on the acBot Cluster Generation System using TruSeq PE 
Cluster Kit V3-cBot-HS (Illumina) according to the manufacturer's instructions. After cluster generation, the library preparations were sequenced on an Illumina Hiseq platform and paired-end reads were generated.

\section{Transcriptome analysis}

An in-house perl script was used to remove low-quality reads. HISAT2 was used to align the remaining reads to the host [22]. The software StringTie (version 1.3.1) was used to map reads to estimate the expression of each gene transcript $[22,23]$. Gene expression levels were estimated by fragments per kilobase of transcript per million fragments mapped (FPKM). Differential expression analyses in the $\mathrm{MH}$ and $\mathrm{MC}$ groups were performed using the DESeq R package (1.10.1). To count the differentially expressed genes (DEGs), an adjusted $P<0.05$ and an absolute value of $\left[\log _{2}\right.$ (fold change) $]>1$ were set as the filter criteria for significantly differential expression. The gene ontology (GO) enrichment analysis of DEGs was carried out by DAVID (version 6.8) [24]. KOBAS (version 3.0) was used to test the statistical enrichment of DEGs in the Kyoto Encyclopedia of Genes and Genomes (KEGG) pathways [25].

\section{Weighted gene co-expression network analysis}

Weighted gene co-expression network analysis (WGCN A) was performed to understand the correlation of host transcriptome with the rumen fermentation parameters and development indexes. All expressed genes (16,329, FPKM $>0.1$ in at least 1 sample) in rumen tissue samples collected from all lambs were used in WGCNA analysis ( $\mathrm{R}$ studio v1.3.1335). After applying the soft thresholding power, a signed network was constructed using the Pearson correlation. Subsequently, a Pearson correlation analysis of genes expression with the rumen fermentation parameters and development indexes of each module (clusters of highly interconnected genes) was performed. Module detection (blockwise modules in WGCNA) functions were performed with the following parameters: max module size was set to 12,000 genes and minimum module size set to 150 genes, and a reassign threshold of 0.25 .

\section{Statistical analysis}

The results of animal performance, ruminal fermentation, blood parameter, and rumen development parameters were analyzed using the one-way ANOVA model in SPSS software (SPSS version 25.0, SPSS, Inc.), with different diet as the main factor. The differences among means were detected by the Turkey's multiple range test. The results presented as means with standard error of the means (SEM). A value of $P<0.05$ was regarded as statistically significant. The DEGs based on transcriptome analysis were analyzed using the Kruskal-Wallis in
SPSS software. The $P$ values were adjusted using the Benjamini-Hochberg method. An adjusted $P<0.05$ and an absolute value of $\left[\log _{2}\right.$ (fold change) $]>1$ were set as the filter criteria for significantly differential expression. Venn analysis was conducted using Venny 2.1 (https:// bioinfogp.cnb.csic.es/tools/venny/ index.html).

\section{Results}

\section{Animal performance}

As shown in Supplemental Fig. 1, BW $(P=0.157)$ of lambs had no significant difference among the three groups at the end of experiment. Compared with MC lambs, the $M$ lambs had lower average daily feed intake (based on dry matter, $P=0.032$ ), but there was no significant difference between $\mathrm{M}$ and $\mathrm{MH}$ lambs during the experiment. The $\mathrm{MH}$ lambs had lower average daily gain (ADG) $(P=0.019)$ than that in MC lambs, but there was no significant difference between $M$ and $M H$ lambs during the experiment.

\section{Ruminal fermentation and blood parameter}

As shown in Table 2, the concentrations of total VFA $(P<0.001)$, acetate $(P<0.001)$, propionate $(P<0.001)$, butyrate $(P<0.001)$, valerate $(P<0.001)$, and MCP $(P<$ 0.001 ) were the highest in the rumen in MC lambs, followed by $\mathrm{MH}$ lambs, and then M lambs. The concentrations of isobutyrate $(P<0.001)$ and isovalerate $(P=$ $0.007)$ were higher in $\mathrm{MH}$ lambs than those in $\mathrm{M}$ and MC lambs. The ruminal $\mathrm{pH}(P<0.001)$ was lower in MC lambs than that in $\mathrm{M}$ and $\mathrm{MH}$ lambs. The concentration of ruminal $\mathrm{NH}_{3}-\mathrm{N}(P<0.001)$ was higher in $\mathrm{M}$ lambs than that in $\mathrm{MH}$ and $\mathrm{MC}$ lambs. There was no significant difference $(P>0.05)$ in the concentrations of glucose, insulin, IGF-1, and BHBA in plasma among the three groups.

\section{Rumen development parameters}

As shown in Table 3, compared with lambs in M group, the lambs in $\mathrm{MH}$ and $\mathrm{MC}$ groups had greater emptied rumen weight $(P<0.001)$, emptied rumen weight/live body weight $(P<0.001)$, and thickness of rumen wall $(P=0.001)$, while there was no significant difference between $\mathrm{MH}$ and $\mathrm{MC}$ lambs. The rumen weight $(P<$ $0.001)$ and thickness of muscles $(P<0.001)$ were highest in $\mathrm{MH}$ lambs, followed by $\mathrm{MC}$ lambs, and then $\mathrm{M}$ lambs. The rumen volume $(P=0.005)$ was greater in $\mathrm{MH}$ lambs than that in M lambs, and there was no significant difference of rumen volume between $\mathrm{MH}$ and MC lambs. The ruminal papilla length $(P<0.001)$, width $(P<0.001)$, ruminal epithelial absorption area $(P<$ $0.001)$, and thickness of total epithelia $(P<0.001)$, stratum corneum (SC, $P<0.001$ ), stratum granulosum (SG, $P<0.001$ ), and stratum spinosum and basale (SS + $\mathrm{SB}, P<0.001)$ were the highest in MC lambs, followed 
Table 2 The effect of alfalfa hay or concentrate starter on ruminal fermentation and blood parameter of pre-weaned lambs $^{1}$

\begin{tabular}{|c|c|c|c|c|c|}
\hline Item & M & $\mathrm{MH}$ & MC & SEM & $P$-value \\
\hline \multicolumn{6}{|c|}{ Ruminal fermentation parameter } \\
\hline $\mathrm{pH}$ & $6.60^{\mathrm{a}}$ & $6.85^{\mathrm{a}}$ & $5.14^{\mathrm{b}}$ & 0.17 & $<0.001$ \\
\hline Total VFA, mmol/L & $8.36^{\mathrm{c}}$ & $99.53^{b}$ & $174.38^{\mathrm{a}}$ & 14.57 & $<0.001$ \\
\hline Acetate, $\mathrm{mmol} / \mathrm{L}$ & $4.21^{c}$ & $67.43^{b}$ & $94.60^{\mathrm{a}}$ & 8.93 & $<0.001$ \\
\hline Propionate, mmol/L & $2.20^{c}$ & $22.89^{b}$ & $43.50^{\mathrm{a}}$ & 3.76 & $<0.001$ \\
\hline Isobutyrate, mmol/L & $0.43^{b}$ & $0.92^{\mathrm{a}}$ & $0.48^{\mathrm{b}}$ & 0.06 & $<0.001$ \\
\hline Butyrate, $\mathrm{mmol} / \mathrm{L}$ & $0.81^{c}$ & $6.46^{\mathrm{b}}$ & $29.34^{a}$ & 3.19 & $<0.001$ \\
\hline |sovalerate, $\mathrm{mmol} / \mathrm{L}$ & $0.55^{\mathrm{b}}$ & $0.80^{\mathrm{a}}$ & $0.51^{\mathrm{b}}$ & 0.04 & 0.007 \\
\hline Valerate, $\mathrm{mmol} / \mathrm{L}$ & $0.17^{c}$ & $1.03^{b}$ & $5.95^{\mathrm{a}}$ & 0.58 & $<0.001$ \\
\hline Acetate: propionate & 2.00 & 3.05 & 2.24 & 0.20 & 0.069 \\
\hline $\mathrm{NH}_{3}-\mathrm{N}, \mathrm{mmol} / \mathrm{L}$ & $11.45^{\mathrm{a}}$ & $3.09^{b}$ & $4.41^{\mathrm{b}}$ & 0.89 & $<0.001$ \\
\hline $\mathrm{MCP}, \mathrm{mg} / \mathrm{mL}$ & $0.20^{c}$ & $0.81^{b}$ & $3.02^{\mathrm{a}}$ & 0.29 & $<0.001$ \\
\hline \multicolumn{6}{|l|}{ Blood parameter } \\
\hline Glucose, $\mathrm{mmol} / \mathrm{L}$ & 6.56 & 5.95 & 6.71 & 0.25 & 0.438 \\
\hline Insulin, $\mu \mid \mathrm{U} / \mathrm{mL}$ & 44.41 & 42.07 & 37.09 & 2.90 & 0.554 \\
\hline IGF-1, ng/mL & 392.06 & 358.67 & 346.80 & 17.01 & 0.588 \\
\hline $\mathrm{BHBA}, \mathrm{mmol} / \mathrm{L}$ & 0.31 & 0.47 & 0.58 & 0.05 & 0.125 \\
\hline
\end{tabular}

${ }^{1}$ Values are shown as means \pm pooled SEM, $n=8$. Mean values within a column with unlike superscript letters were significantly different $(P<0.05) . M$ goat milk group, $M H$ goat milk plus alfalfa hay group, $M C$ goat milk plus concentrate diet group, VFA volatile fatty acids, MCP microbial crude protein, IGF-1 insulin-like growth factor 1, BHBA $\beta$-hydroxybutyric acid by $\mathrm{MH}$ lambs, and then $\mathrm{M}$ lambs. The density $(P<$ 0.001 ) of ruminal papilla was greater in $M$ lambs than that in $\mathrm{MH}$ and $\mathrm{MC}$ lambs.

\section{Transcriptional profile in the rumen tissue}

A total of 501.81 million ( $41.82 \pm 1.36$ million reads per sample) high quality, paired reads generated from 12 rumen tissue samples, and the overall read alignment rate to the Ovis aries reference genome was $81 \% \pm$ $2.22 \%$. The principal components analysis (PCA) of total gene expression in rumen tissue samples demonstrated the marked clustering between 3 groups (Fig. 1a). There were 544 genes were significantly differentially expressed in the $\mathrm{MH}$ group compared with the $\mathrm{M}$ group, including 220 upregulated and 324 downregulated genes. One thousand one hundred and eight genes were significantly differentially expressed in the MC group compared with the $\mathrm{M}$ group, including 543 upregulated and 565 downregulated genes (Fig. 1c). As shown in Fig. 1b, Venn diagram showed there were 312 shared DEGs between the "MH vs. M" and "MC vs. M", and 232 and 796 unique DEGs observed in the "MH vs. M" and "MC vs. M", respectively.

\section{Functional analysis of 312 shared DEGs in the rumen} tissue between "MH vs. M" and "MC vs. M"

A total of 92 biological process (BP) terms were significantly enriched out of which $43.48 \%$ were related to

Table 3 The effect of alfalfa hay or concentrate starter on rumen weight, volume, and ruminal papillae morphology of pre-weaned lambs $^{1}$

\begin{tabular}{|c|c|c|c|c|c|}
\hline Item & M & MH & MC & SEM & $P$-value \\
\hline \multicolumn{6}{|l|}{ Rumen weight and volume } \\
\hline Rumen weight, $g$ & $371.13^{c}$ & $1242.50^{\mathrm{a}}$ & $749.63^{b}$ & 83.74 & $<0.001$ \\
\hline Emptied rumen weight, $g$ & $51.80^{\mathrm{b}}$ & $154.00^{\mathrm{a}}$ & $172.50^{\mathrm{a}}$ & 11.72 & $<0.001$ \\
\hline Emptied rumen weight/live body weight, \% & $0.53^{\mathrm{b}}$ & $1.80^{\mathrm{a}}$ & $1.75^{\mathrm{a}}$ & 0.13 & $<0.001$ \\
\hline Rumen volume, mL & $716.25^{\mathrm{b}}$ & $1528.75^{\mathrm{a}}$ & $1199.38^{\mathrm{ab}}$ & 111.12 & 0.005 \\
\hline \multicolumn{6}{|l|}{ Papillae morphology } \\
\hline Length, mm & $0.65^{\mathrm{C}}$ & $1.79^{\mathrm{b}}$ & $2.44^{\mathrm{a}}$ & 0.07 & $<0.001$ \\
\hline Width, mm & $0.49^{c}$ & $0.80^{\mathrm{b}}$ & $1.32^{\mathrm{a}}$ & 0.04 & $<0.001$ \\
\hline Density, $\mathrm{n}$ & $310.00^{\mathrm{a}}$ & $211.00^{\mathrm{b}}$ & $158.00^{\mathrm{b}}$ & 15.38 & $<0.001$ \\
\hline Surface, $\mathrm{mm}^{2} / \mathrm{cm}^{2}$ & $195.14^{c}$ & $577.69^{b}$ & $1006.69^{a}$ & 84.82 & $<0.001$ \\
\hline \multicolumn{6}{|l|}{ Thickness of different stratum } \\
\hline Total epithelia, $\mu \mathrm{m}$ & $90.78^{c}$ & $123.91^{\mathrm{b}}$ & $216.03^{\mathrm{a}}$ & 3.00 & $<0.001$ \\
\hline Stratum corneum, $\mu \mathrm{m}$ & $13.42^{c}$ & $31.47^{\mathrm{b}}$ & $48.78^{\mathrm{a}}$ & 0.75 & $<0.001$ \\
\hline Stratum granulosum, $\mu \mathrm{m}$ & $13.11^{c}$ & $17.64^{b}$ & $36.00^{a}$ & 0.42 & $<0.001$ \\
\hline Stratum spinosum and basale, $\mu \mathrm{m}$ & $64.25^{b}$ & $74.81^{b}$ & $131.25^{\mathrm{a}}$ & 2.43 & $<0.001$ \\
\hline Muscles layer, $\mu \mathrm{m}$ & $742.73^{c}$ & $1006.08^{\mathrm{a}}$ & $856.71^{b}$ & 20.46 & $<0.001$ \\
\hline Rumen wall, $\mu \mathrm{m}$ & $1093.72^{b}$ & $1276.35^{\mathrm{a}}$ & $1246.72^{\mathrm{a}}$ & 22.86 & 0.001 \\
\hline
\end{tabular}

${ }^{1}$ Values are shown as means \pm pooled SEM, $n=8$. Mean values within a column with unlike superscript letters were significantly different $(P<0.05)$. $M$ goat milk group, $M H$ goat milk plus alfalfa hay group, $M C$ goat milk plus concentrate diet group 
immune function, $36.96 \%$ were associated with nutrient transport and metabolism, 3.26\% were linked to cell activation, while $2.17 \%$ were related to cell adhesion, and $1.09 \%$ to growth (Fig. 1e). The BP terms associated with immune function were divided into the classes of cytokine production, immune response, and immunocyte activation. The BP terms related to nutrient transport and metabolism were mainly divided into the classes of ion transport, lipid transport and metabolism, and nucleoside metabolic process (Supplemental Table 1). The DEGs were enriched in bicarbonate transport and ion transporter involved in VFA absorption including $C A 4$, SLC26A3, and SLC26A9 (Fig. 1j).

The results of KEGG pathway analysis showed that 18 pathways were significantly enriched (Fig. 2b). The pathways that were most enriched included metabolic pathways, PPAR signaling pathway (PLIN2, ME1, HMGCS2, LPL, and LOC101111528), butanoate metabolism (HMGCL, HMGCS2, and ACSM3), synthesis and degradation of ketone bodies (HMGCL and HMGCS2), and mineral absorption (SLC26A3, CLCN2, and $S L C 26 A 9)$ which is associated with VFA absorption and metabolism.

\section{Weighted gene co-expression network analysis of the correlation of host transcriptome with the rumen fermentation parameters and development indexes}

The use of WGCNA clustered the genes expressed in all rumen tissues into 22 gene modules (M1-M22). The two most significant modules, M16 (2,052 genes) and M18 (579 genes), showed a positive correlation with the rumen fermentation parameters and development indexes except for the concentration of isobutyrate and isovalerate (Fig. 3a). The BP terms of M16 and M18 were shown in Supplemental Table 2.

M16 module was related to many metabolism pathways, including carbon metabolism, cysteine and methionine metabolism, propanoate metabolism, pyruvate metabolism, fatty acid metabolism, citrate cycle, butanoate metabolism, glycolysis/gluconeogenesis, and synthesis and degradation of ketone bodies (Fig. 3c). The DEGs that were involved in these metabolism pathways including FBP1, AHCYL2, TST, HMGCL, HMGCS2, and PCK2, were significantly upregulated both in the $\mathrm{MH}$ and $\mathrm{MC}$ groups (Supplemental Table 3). M18 module was mainly enriched with the Wnt signaling pathway, cell cycle, PI3K-Akt signaling pathway, mTOR signaling pathway, Notch signaling pathway, p53 signaling pathway, DNA replication, and apoptosis-multiple species (Fig. 3b). Also, many genes involved in ruminal epithelial proliferation and apoptosis were discovered, including TP53, CCND1, CCNB2, CASP3, and CASP8.

\section{Function analysis of 223 DEGs observed in the rumen tissue of $\mathrm{MC}$ vs. $\mathrm{MH}$}

Two hundred and twenty-three genes were significantly differentially expressed in the MC group compared with the $\mathrm{MH}$ group, including 114 upregulated and 109 downregulated genes (Supplemental Fig. 2A). A total of 29 BP terms were significantly enriched out of which $17.24 \%$ were related to immune function, $17.24 \%$ were associated with nutrient transport and metabolism, $13.79 \%$ were linked to growth, $13.79 \%$ were associated response to stimulus, while $6.89 \%$ were related to muscle system process, and $3.45 \%$ to cell adhesion (Supplemental Fig. 2B). Six up-regulated genes (CXCL8, IL36A, $F A B P 4, I L 1 A, I L 1 B$, and $K R T 1)$ and 4 down-regulated genes (NOS2, TSPAN2, SCN9A, and VNN1) were enriched in the $\mathrm{BP}$ associated with inflammatory response. Four genes (IL1A, IL36A, IL36RN, and EREG) involved in the cytokine production were upregulated. Additionally, five DEGs (GNMT, PSAT1, ARG1, ODC1, and $S D S$ ) related to cellular amino acid metabolic process, were significantly downregulated, and seven genes (GNMT, SCD, PSAT1, FABP4, ARG1, ODC1, and $S D S$ ) associated with carboxylic acid metabolic process, were significantly upregulated (Supplemental Fig. 2D).

The results of KEGG pathway analysis showed that 27 pathways, mainly related to amino acid metabolism (biosynthesis of amino acids, glycine, serine and threonine metabolism, arginine and proline metabolism, and arginine biosynthesis.) and immune function (cytokine-cytokine receptor interaction, IL-17 signaling pathway, tolllike receptor signaling pathway, TNF signaling pathway, and viral protein interaction with cytokine and cytokine receptor), were significantly enriched (Supplemental Fig. 2C).

\section{Function analysis of 232 unique DEGs observed in the rumen tissue of $\mathrm{MH}$ vs. $\mathrm{M}$}

A total of $61 \mathrm{BP}$ terms were significantly enriched out of which $52.46 \%$ were related to immune function while $11.48 \%$ were associated with nutrient transport and metabolism. Other BP terms affected include those related to cell adhesion (11.48\%), growth (9.84\%), and signaling pathway (6.56\%) (Fig. 1d). The BP terms associated with immune function were divided into the classes of cytokine production, immune response, immunocyte activation, and the Toll-like receptor signaling pathway (Supplemental Table 4). The BP terms associated with cytokine production included regulation of cytokine production, cytokine production, and positive and negative regulation of cytokine production. Ten genes involved in the cytokine production were downregulated, including C5, CD28, IL36A, IRF7, LEF1, LOC101119706, NLRC3, PGLYRP2, PTPN22, and SLAMF1 (Fig. 1g). Additionally, BP associated with 


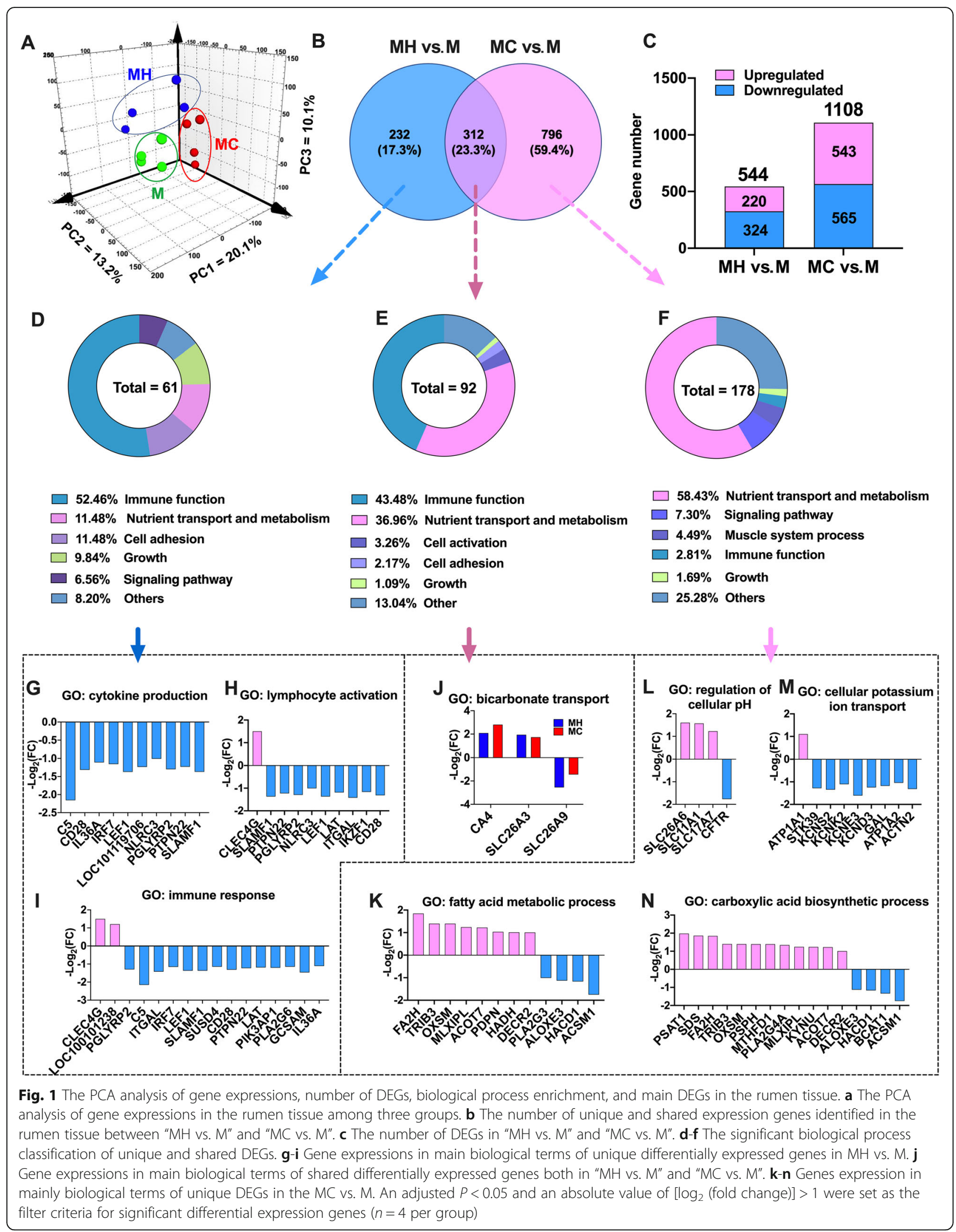




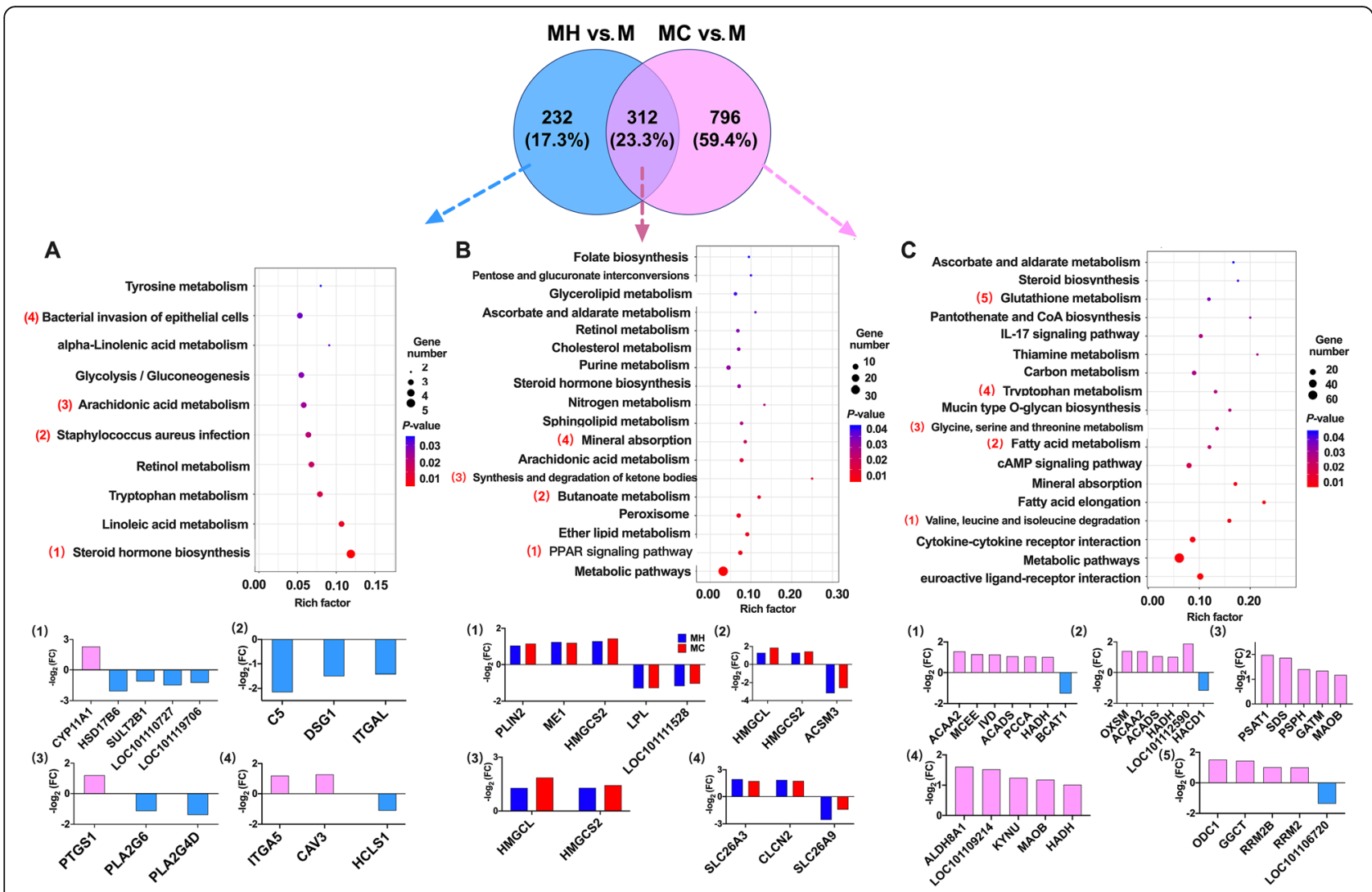

Fig. 2 The KEGG pathways significantly enriched in the unique (a and $\mathbf{b}$ ) and shared (c) DEGs identified in the rumen wall between "MH vs. M" and "MC vs. M", and DEGs in main KEGG pathways. The significance of identified KEGG pathways was determined by $P<0.05$

immune response included immune effector process, immune response, regulation of immune system process, and regulation of immune response. Fourteen down-regulated DEGs (C5, ITGAL, IRF7, LEF1, SLAM F1, SUSD4, CD28, PTPN22, LAT, PIK3AP1, PLA2G6, GCSAM, and IL36A) and 2 up-regulated DGEs (CLEC4G and LOC100101238) were enriched in the BP associated with immune response (Fig. 1i). The BPs associated with immunocyte activation included leukocyte cell-cell adhesion, lymphocyte activation, leukocyte activation, and leukocyte differentiation. Nine down-regulated DEGs (SLAMF1, PTPN22, PGLYRP2, NLRC3, LEF1, LAT, ITGAL, IKZF1, and CD28) were enriched in the BP associated with lymphocyte activation (Fig. 1h).

The results of KEGG pathway analysis showed that 10 pathways were significantly enriched (Fig. 2a), including steroid hormone biosynthesis (CYP11A1, HSD17B6, SULT2B1, LOC101110727, and LOC101119706), Staphylococcus aureus infection (C5, DSG1, and ITGAL), arachidonic acid metabolism (PTGS1, PLA2G6, and $P L A 2 G 4 D)$, and bacterial invasion of epithelial cells (ITGA5, CAV3, and HCLS1).
Function analysis of 796 unique DEGs observed in the rumen tissue of $M C$ vs. $M$

A total of $178 \mathrm{BP}$ terms were significantly enriched out of which $58.43 \%$ were related to nutrient transport and metabolism while $7.30 \%$ were associated to signaling pathway. Other BP terms affected include those related to muscle system process $(4.49 \%)$, immune function (2.81\%), and growth (1.69\%) (Fig. 1f). The BP terms related to nutrient transport and metabolism were mainly divided into the classes of ion transport, nitrogen transport and metabolism, and lipid transport and metabolism (Supplemental Table 5). The BPs associated with ion transport included cellular potassium ion transport, potassium ion transmembrane transport, negative regulation of ion transmembrane transporter activity, and regulation of intracellular pH. Four DEGs, KCND3, KCNE3, KCNK2, and $K C N S 2$, in potassium transporter BP were significantly downregulated (Fig. $1 \mathrm{~m}$ ), and three genes, SLC26A6, SLC11A1, and SLC17A7, in regulation of intracellular $\mathrm{pH}$, were significantly upregulated (Fig. 11). The BPs associated with nitrogen transport and metabolism included nitrogen compound transport, carboxylic acid biosynthetic process, amide transport, and peptide transport. 


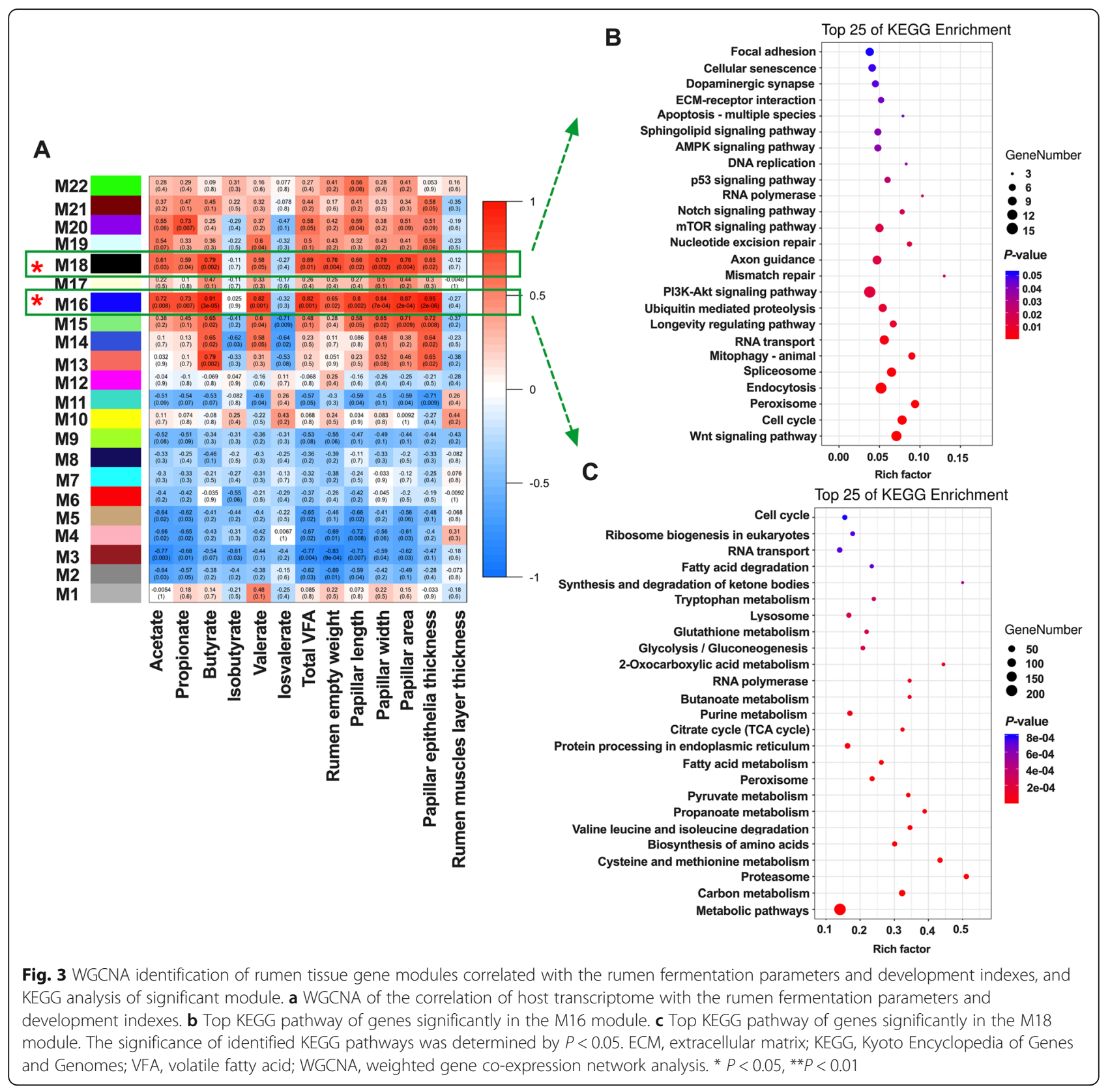

The genes expression belonging to the carboxylic acid biosynthetic process was shown in Fig. 1n. The BP associated with lipid transport and metabolism included fatty acid biosynthetic process, lipid metabolic process, positive regulation of lipid transport, fatty acid metabolic process, lipid transport, and so on. Eight up-regulated genes and 4 down-regulated genes enriched in the fatty acid metabolic process were shown in Fig. 1k.

The results of KEGG pathway analysis showed that 18 pathways were significantly enriched (Fig. 2c). Most KEGG pathways were associated with amino acid and fatty acid metabolisms, such as valine, leucine and isoleucine degradation (ACAA2, MCEE, IVD, ACADS, PCCA,
$H A D H$, and $B C A T 1)$, glycine, serine and threonine metabolism (PSAT1, SDS, PSPH, GATM, and MAOB), tryptophan metabolism (ALDH8A1, LOC101109214, KYNU, $M A O B$, and $H A D H$ ), glutathione metabolism (ODC1, GGCT, RRM2B, RRM2, and LOC101106720), and fatty acid metabolism (OXSM, ACAA2, ACADS, HADH, LOC101112590, and HACD1).

\section{Discussion}

In the present study, a 42-day-old liquid feeding lamb model was established to eliminate the effect of age on the experiment. Meanwhile, lambs in $\mathrm{MH}$ and $\mathrm{MC}$ groups were fed a uniform amount of liquid feed to 
ensure that a starter diet was the unique impact factor. Volatile fatty acids as energy production during its metabolism may directly stimulate rumen morphological development. Moreover, alfalfa hay introduction tended to affect the immune function of the rumen wall, while concentrate starter enhanced nutrient transport and metabolism function. These findings gained a comprehensive understanding of the regulatory mechanisms of the rumen wall morphological and functional development induced by different solid diet regimens, and provided new insights into the improvement of rumen wall development by nutritional strategies in young ruminants.

\section{Rumen fermentation and development}

In the present study, compared with pure milk feeding, hay and concentrate starter did not affect ADG and BW of lambs, but the ADG of the MH lambs were lower than that in $\mathrm{MC}$ group. This could be explained by the lower ME contained in alfalfa hay than concentrate starter [26]. Compared with pure milk, alfalfa hay and concentrate introduction provides more carbon and nitrogen source for MCP and VFA synthesis in rumen [27, 28], which may explain the increase of rumen MCP and VFA concentrations with hay and concentrate starter introduction. Previous studies demonstrated that VFA was an important factor promoting rumen development [29]. The results of rumen morphological changes showed that alfalfa hay and concentrate starter introduction both positively affected rumen weight, volume, papillae surface, and thickness of rumen epithelium, which were consistent with previous studies $[5,10$, $11,30]$. Previous studies indicated that hay introduction especially increased the volume of the rumen and thickness of rumen muscle in young ruminants, while concentrate starter introduction especially increased rumen weight and rumen papilla surface [9-11]. The largest volume and muscle layer thickness of rumen wall were found in the $\mathrm{MH}$ group, while the largest absorption and thickness of ruminal epithelia were found in the $\mathrm{MC}$ group.

\section{Molecular mechanisms involved in rumen wall morphological and functional development by transcriptome analysis}

Three hundred and twelve shared DEGs, observed both in the $\mathrm{MH}$ vs. $\mathrm{M}$ and $\mathrm{MC}$ vs. M, may play a central role in promoting rumen wall morphological and functional development. These genes are mainly enriched in the biological processes of immune function and nutrient transport and metabolism, indicating that immune function and nutrient transport and metabolism play an important role in the development of the rumen. Meanwhile, immune function and nutrient transport and metabolism are the main functions of hay and concentrate, respectively, so these two parts are mainly discussed in the following specific functions of hay and concentrate. In the present study, the genes expression of $C A 4$ and $S L C 26 A 3$, enriched in bicarbonate transport and ion transport, were increased both in the $\mathrm{MH}$ and $\mathrm{MC}$ group, and have been shown to participate in the ruminal absorption of VFA [31]. Moreover, the PPAR signaling pathway, butanoate metabolism, and synthesis and degradation of ketone bodies were found to be the most significantly enriched signal pathways in ruminal tissue with alfalfa hay or concentrate starter introduction, which are involved in VFA metabolism [32, 33]. Therefore, volatile fatty acid is a common medium for the development of rumen by hay and concentrate starter.

Weighted gene co-expression network analysis was conducted to further explore the relationship between VFA and rumen wall morphology. Two most significant modules, M16 and M18, were found in the present study. During BP analysis of genes in the M16 module, up-regulated organic acid metabolic processes and ATP metabolic biological processes were highlighted as the characteristics of rumen wall development. Meanwhile, increased carbon metabolism, propanoate metabolism, pyruvate metabolism, citrate cycle, butanoate metabolism, and synthesis and degradation of ketone bodies pathways were also found as features of rumen wall development. These results were partly consistent with Naeem et al. who not only indicated that the metabolism of pyruvate, VFA, and long-chain fatty acids, were increased in rumen epithelia of the calf in response to enhanced plane of nutrition but also clarified that PPAR may be an important signal pathway to promote rumen metabolism and development [32]. Similarly, during the analysis of shared DEGs, the PPAR signaling pathway was the most significantly changed pathway induced by alfalfa hay or concentrate starter. Previous studies indicated that the mitotic process is a highly endoenergetic process, and important in promoting rumen epithelial development and growth, especially $\mathrm{G}_{1}$ period [34-36]. Interestingly, the expression of $C C N E$, enriched in the cell cycle pathway, was increased in the rumen tissue of the $\mathrm{MH}$ and $\mathrm{MC}$ group. Specifically, CCNE stability may depend on mitochondrial ATP producing capacity [37]. Therefore, stabilization of $C C N E$ during $\mathrm{G}_{1}-\mathrm{S}$ transition may be caused by increased VFA metabolism after solid diet introduction. In addition, the genes in M18 are mainly enriched in signal transduction, including Wnt signaling pathway, PI3K-Akt signaling pathway, mTOR signaling pathway, Notch signaling pathway, p53 signaling pathway, and AMPK signaling pathway. These signaling pathways were closely related to cell proliferation, apoptosis, and differentiation [36, 38-41]. However, the main genes enriched in the KEGG pathway of signal transduction were not affected by solid diet introduction. Therefore, the energy production during VFA metabolism may drive the rumen wall development directly, and 
the PPAR signaling pathway may be the link between VFA metabolism and rumen development.

\section{The different molecular and biological processes involved in rumen wall morphological and functional development between hay and concentrate starter introduction}

In the present study, two hundred and twenty-three genes were differentially expressed in the $\mathrm{MC}$ vs. $\mathrm{MH}$ group. The mainly enriched biological process were related to the immune function and nutrient transport and metabolism of rumen tissue. Here, the expression of genes related to interleukins production were lower in $\mathrm{MH}$ than MC, including IL1A, IL1B, IL36A, IL36RN, IL36G, and IL12RB2. These genes also enriched in the pathway of cytokine-cytokine receptor interaction, IL-17 signaling pathway, Toll-like receptor signaling pathway, TNF signaling pathway, and viral protein interaction with cytokine receptor. The decreased expression of immune-related genes (including ILs, TNF, and TLRs) has been reported in rumen tissue of lambs when fed solid diet [42, 43]. These results suggested there is greater resistance to inflammation within the rumen tissue in $\mathrm{MH}$ than MC lambs. Furthermore, compared with $\mathrm{MH}$ lambs, the upregulated genes (GNMT, PSAT1, ARG1, $O D C 1$ and $S D S$ ) in MC lambs, were involved in cellular amino acid metabolic process, carboxylic acid metabolic process, and the pathway of many amino acid metabolism, indicating enhanced amino acid metabolism in the rumen tissue. These results indicated that hay and concentrate starter exert distinct influences on the rumen wall functional development in pre-weaned lambs. Thus, in the present study, the specific biological processes upon hay or concentrate starter regimes were further investigated.

The specific molecular and biological processes involved in rumen wall morphological and functional development by hay introduction

To clarify the special functional genes and biological processes when alfalfa hay was introduced, the analysis of the biological functions of the 232 unique DEGs (MH vs. M) were performed. Interestingly, the most enriched biological process was related to the immune function of rumen tissue. According to our findings, alfalfa hay introduction downregulated the cytokine production process. The down-regulated DEGs of IL36A, CD28, SLAMF1, LEF1, and PGLYRP2 reduced the production of pro-inflammatory factors, such as IL36, IL-2, TNF- $\alpha$, IL-1 $\beta$, and IL-6 [44-48]. Moreover, the unique upregulated gene $(C L E C 4 G)$ and down-regulated genes (ITGAL and LAT) in the $\mathrm{MH}$ group were enriched in immune response and lymphocyte activation, which may reduce immune and inflammatory responses in rumen tissue [49-51]. Previous studies showed that high VFA concentration decreased the expression of genes involved in cholesterol biosynthesis in the rumen epithelia $[11,52]$. Similarly, in the present study, the cholesterol decomposition process in steroid hormone biosynthesis was downregulated by alfalfa hay introduction, which may be explained by high VFA production in the rumen. In addition, alfalfa hay introduction also downregulated the arachidonic acid production process, proved by decreased PLA2G4 and PLA2G6. It is well established that cholesterol and arachidonic acid regulate cellular inflammation, oxidative stress, proliferation, and membrane permeability $[52,53]$, which may affect the rumen immune function. Previous studies indicated that ruminal epithelial cells recognize microbial components through Toll-like receptors and PGLYRPs $[1,54]$. The decreased PGLYRP2 expression in $\mathrm{MH}$ may be resulted from the establishment of microbial immune tolerance and important for minimizing harmful inflammatory responses $[1,54]$. In the present study, the unique DEGs in MH significantly enriched in the bacterial invasion of epithelial cells and Staphylococcus aureus infection pathway. In these DEGs, ITGA5 and CAV3 can effectively prevent pathogens from invading host cells [55] and regulate host immune response to the majority of bacterial invasion by promoting bacterial clearance [56], respectively. DSG1 is the specific receptor for exfoliative toxin A cleavage and essential for the promotion of staphylococcus adhesion to host cells [57]. Moreover, the decreased expression of the lipopolysaccharide binding protein $(L B P)$ was also observed in alfalfa hay supplementation. Taking these results together, hay supplementation may be beneficial to maintain the healthy rumen development. Thus, future studies are needed to focus on the bacteria structure as well as the concentration of lipopolysaccharide in the rumen content and epithelium to define their roles in affecting rumen tissue gene expression and its relationship with immune response.

\section{The specific molecular and biological processes involved in rumen wall morphological and functional development by concentrate starter introduction}

The biological functions analysis of the 796 unique DEGs (MC vs. M) showed that concentrate starter introduction especially affected the nutrient transport and metabolism in rumen tissue. The unique up-regulated SLC26A6 in the MC group involved in the regulation of cellular $\mathrm{pH}$ has been extensively studied in rumen VFA absorption [58]. Moreover, lower expression of KCND3, $K C N E 3, K C N K 2$, and $K C N S 2$ enriched in cellular potassium ion transport and potassium ion transmembrane transport were suggestive of lower ammonia absorption in the rumen epithelia of lambs fed concentrate starter $[59,60]$. This may be the reason of low $\mathrm{NH}_{3}-\mathrm{N}$ concentration in the rumen of lambs fed concentrate starter. 
Previous study indicated that ammonia reduced the rate of endogenous urea transfer to the lumen of the gastrointestinal tract [61]. Likewise, enrichment in the nitrogen compound transport process was observed as well as a significant increase in the expression of SLC14A1, formerly known as urea transfer protein [62], which suggested increased transport of urea from the blood into the rumen. Therefore, these results demonstrated that concentrate starter introduction increased the rumen urea-N recycling and nitrogen utilization. It is of note that we also found many signaling pathways involved in the amino acid metabolism. Previous studies indicated that a comparatively low amount of amino acids and peptides may be absorbed and metabolized by the rumen tissue [63-65]. Moreover, the development of a rumen wall needs increased cell and protein turnover [66-68]. Previous studies showed that amino acids were absorbed by the animal host in the intestine and transferred to organ tissues for protein synthesis and oxidation [69, 70]. Taking these results together, we speculated that the synthesis of MCP in the rumen promoted protein turnover and oxidation in the rumen tissue, no matter where it was absorbed (rumen or the intestine). In the present study, 6 upregulated DEGs were annotated in the valine, leucine, and isoleucine degradation. Meanwhile, the glycine, serine and threonine metabolism and tryptophan metabolism were upregulated in concentrate starter introduction. These metabolites are the substrates of the citric acid cycle, generating energy-containing compounds, including NADH, FADH, and ATP. They are responsible for the activation of some biological processes and might further promote rumen wall development [14]. Fatty acids are essential metabolic fuels and are vital for cell proliferation in cellular membranes [32]. In the present study, many unique DEGs were annotated in fatty acid metabolism and fatty acid elongation upon the introduction of concentrate starter, which was beneficial to the proliferation and turnover of rumen epithelial cells. Therefore, the above results provide evidence for the critical role of the nutrient absorption and metabolism in the rumen wall functional development with concentrate starter introduction.

\section{Conclusions}

In summary, VFA plays a major role in promoting rumen development, as energy production during VFA metabolism may directly stimulate rumen development. Moreover, the hay/concentrate starter drives rumen wall morphological and functional development in the special biological process of pre-weaning lambs. Alfalfa hay introduction primarily enhanced the ability of rumen epithelium to resist bacterial invasion and facilitated

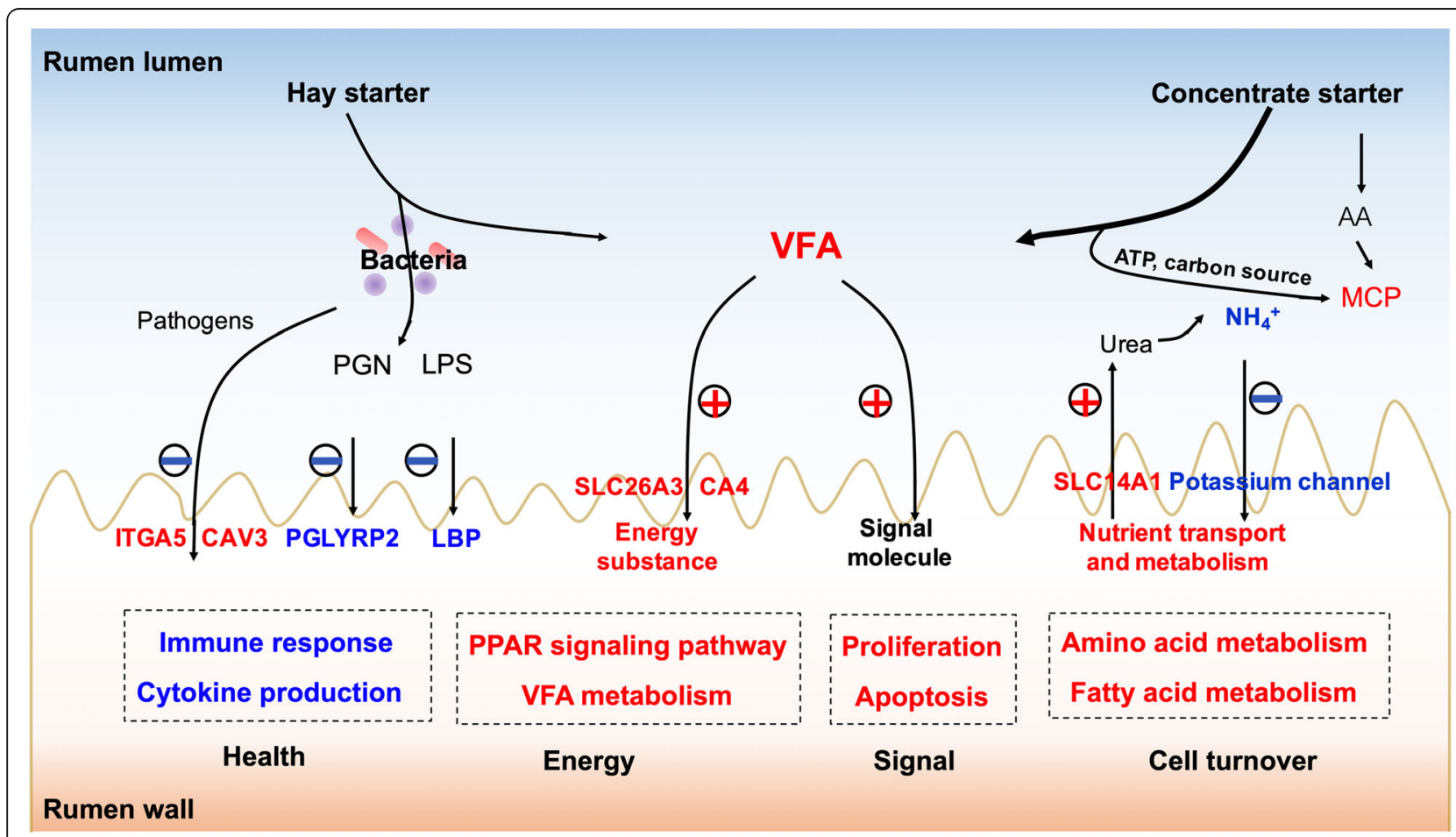

Fig. 4 Summary of clarifying how different solid diet regimens (hay or concentrate) drive rumen wall development and characterize their shared and unique biological process between "MH vs. M" and "MC vs. M". The plus sign represents upregulated or activation, and the minus sign represents downregulated or inhibition. AA, amino acid; LPS, lipopolysaccharide; LBP, LPS binding protein; MCP, microbial crude protein; VFA, volatile fatty acid 
establishment of the immune function in the rumen wall of pre-weaned lambs. While, concentrate starter introduction was likely to promote the nutrient metabolism function and increased amino acid and fatty acid metabolism in the rumen tissue (Fig. 4). The functions of immune metabolism in the rumen wall are closely related to animal health and production performance. Therefore, in ruminant production, to promote efficient and healthy animal performance, the special impacts of hay and concentrate starter introduction on the morphological and functional development of the rumen wall should be fully considered.

\section{Supplementary Information}

The online version contains supplementary material available at https://doi. org/10.1186/s40104-021-00556-4

Additional file 1: Supplemental Table 1. The main biological process enrichment analysis of shared DEGs both in $\mathrm{MH}$ and MC group lambs. Supplemental Table 2. Top 20 biological process terms significantly enriched in the M16 and M18 module. Supplemental Table 3. Top 25 KEGG pathway terms significantly enriched in the M16 and M18 module. Supplemental Table 4. The BP terms associated with immune function were enriched from unique DEGs observed in the $\mathrm{MH}$ vs. $\mathrm{M}$.

Supplemental Table 5. The BP terms associated with nutrient transport and metabolism were enriched from unique DEGs observed in the MC vs. M. Supplemental Fig. 1. Effect of alfalfa hay or concentrate starter on the ADFI (A), ADG (B), and BW (C) of pre-weaned lambs. Values are shown as means \pm pooled SEM $n=8$. Mean values within a column with unlike superscript letters were significantly different $(P<0.05)$. M, goat milk group; $\mathrm{MH}$, goat milk plus alfalfa hay group; $\mathrm{MC}$, goat milk plus concentrate diet group; ADFI, average daily feed intake; ADG, average daily gain; BW, body weight. Supplemental Fig. 2. The comparison of $M C$ and $\mathrm{MH}$ in transcriptome analysis. A. The number of DEGs identified in MC vs MH. B. The significant biological process classification of DEGs. C. The significantly enriched KEGG pathways of DEGs. D. Genes expression in mainly biological terms of DEGs. E. Genes expression in mainly KEGG pathways of DEGs. An adjusted $P<0.05$ and an absolute value of $\left[\log _{2}\right.$ (fold change)] $>1$ were set as the filter criteria for significant differential expression genes ( $n=4$ per group). The significance of identified KEGG pathways was determined by $P<0.05$

\footnotetext{
Abbreviations

AHCYL2: Adenosylhomocysteinase like 2; BHBA: $\beta$-Hydroxybutyric acid; BP: Biological process; BW: Body weight; CA4: Carbonic anhydrase 4; CASPs: Caspases; CCNs: Cyclins; DEGs: Differentially expressed genes; FBP1: Fructose-bisphosphatase 1; FPKM: Fragments per kilobase of transcript per million fragments mapped; GPRs: G protein-coupled receptors; HDACs: Histone deacetylases; HMGCL: 3-Hydroxy-3-methylglutaryl-CoA lyase; HMGCS2: 3-Hydroxy-3-methylglutaryl CoA synthase 2; KCND3: Potassium voltage-gated channel subfamily D member 3; KCNE3: Potassium voltagegated channel subfamily E member 3; KCNK2: Potassium voltage-gated channel subfamily K member 2; KCNS2: Potassium voltage-gated channel subfamily S member 2; KEGG: Kyoto Encyclopedia of Genes and Genomes; M: Goat milk powder only; MC: Goat milk powder + concentrate starter;

MCP: Microbial crude protein; ME: Metabolic energy; MH: Goat milk powder + alfalfa hay; $\mathrm{NH}_{3}-\mathrm{N}$ : Ammonia nitrogen; PCA: Principal components analysis; PCK2: Phosphoenolpyruvate carboxykinase 2; PGLYRP2: Peptidoglycan recognition proteins 2; PLA2G4: Phospholipase A2 group 4; SLC11A1: Solute carrier family 11 member 1; SLC17A7: Solute carrier family 17 member 7; SLC26A6: Solute carrier family 26 member 6; TP53: Tumor protein p53; TST: Thiosulfate sulfurtransferase; VFAs: Volatile fatty acids; WGCNA: Weighted gene co-expression network analysis
}

\section{Acknowledgments}

The authors would like to thank Leluo Guan from the University of Alberta for the suggestions on the analysis method.

\section{Authors' contributions}

DMS, JHL, and SYM designed the research; DMS, LXL and YYY conducted the research; JHL and DMS analyzed the data and wrote the paper; CZG helped with the manuscript writing; WYZ provided essential laboratories and instruments, and JHL had primary responsibility for the final content. All authors read and approved the final manuscript.

\section{Funding}

This work was supported by the Project for Top Young Talents Program of College of Animal Science and Technology of Nanjing Agricultural University (DKQB201904), National Key Research and Development Plan

(2018YFD0501900), Postgraduate Research \& Practice Innovation Program of Jiangsu Province (KYCX20_0603), and Science and Technology Project of Huzhou City of China (2017GY18).

\section{Availability of data and materials}

The datasets used and analyzed during the current study are available from the corresponding author on reasonable request.

\section{Ethics approval and consent to participate}

This study was conducted following the guidance of the Animal Care and Use Committee of Nanjing Agricultural University in China.

\section{Consent for publication}

Not applicable.

\section{Competing interests}

The authors declare no conflicts of interest.

\section{Author details}

'Jiangsu Key Laboratory of Gastrointestinal Nutrition and Animal Health, Laboratory of Gastrointestinal Microbiology, College of Animal Science and Technology, Nanjing Agricultural University, Nanjing 210095, Jiangsu Province, China. ${ }^{2}$ National Center for International Research on Animal Gut Nutrition, Nanjing Agricultural University, Nanjing 210095, China. ${ }^{3}$ National Experimental Teaching Demonstration Center of Animal Science, Nanjing Agricultural University, Nanjing 210095, China. ${ }^{4}$ Huzhou Academy of Agricultural Sciences, Huzhou 313000, China.

Received: 26 August 2020 Accepted: 12 January 2021

Published online: 10 March 2021

\section{References}

1. Yanez-Ruiz DR, Abecia L, Newbold CJ. Manipulating rumen microbiome and fermentation through interventions during early life: a review. Front Microbiol. 2015;6:1133

2. Kon SK, Porter JW. The intestinal synthesis of vitamins in the ruminant. Vitam Horm. 1954;12:53-68.

3. Flint HJ, Bayer EA, Rincon MT, Lamed R, White BA. Polysaccharide utilization by gut bacteria: potential for new insights from genomic analysis. Nat Rev Microbiol. 2008;6:121-31

4. Russell JB, Rychlik JL. Factors that alter rumen microbial ecology. Science. 2001;292:1119-22.

5. Jiao JZ, Li XP, Beauchemin KA, Tan ZL, Tang SX, Zhou CS. Rumen development process in goats as affected by supplemental feeding $\mathrm{v}$. grazing: age-related anatomic development, functional achievement and microbial colonisation. Brit J Nutr. 2015;113:888-900.

6. Bannink A, France J, Lopez S, Gerrits WJJ, Kebreab E, Tamminga S, et al. Modelling the implications of feeding strategy on rumen fermentation and functioning of the rumen wall. Anim Feed Sci Technol. 2008;143:3-26.

7. Wise GH, Anderson GW. Factors affecting the passage of liquids into the rumen of the dairy calf. I. Method of administering liquids: drinking from open pail versus sucking through a rubber nipple. J Dairy Sci. 1939;22:697-705.

8. Wardrop I. Some preliminary observations on the histological development of the fore-stomachs of the lamb II. The effects of diet on the histological 
development of the fore-stomachs of the lamb during post-natal life. J Agric Sci. 1961;57:343-6.

9. Stobo I, Roy J, Gaston HJ. Rumen development in the calf: 2. The effect of diets containing different proportions of concentrates to hay on digestive efficiency. Brit J Nutr. 1966;20:189-215.

10. Beiranvand H, Ghorbani GR, Khorvash M, Nabipour A, Dehghan-Banadaky M, Homayouni A, et al. Interactions of alfalfa hay and sodium propionate on dairy calf performance and rumen development. J Dairy Sci. 2014;97:2270-80.

11. Sun DM, Mao SY, Zhu WY, Liu JH. Effect of starter diet supplementation on rumen epithelial morphology and expression of genes involved in cell proliferation and metabolism in pre-weaned lambs. Animal. 2018;12:2274-83.

12. Castells $L$, Bach A, Aris A, Terre M. Effects of forage provision to young calves on rumen fermentation and development of the gastrointestinal tract. J Dairy Sci. 2013;96:5226-36.

13. Connor EE, Baldwin RL t, Walker MP, Ellis SE, Li C, Kahl S, et al. Transcriptional regulators transforming growth factor-beta1 and estrogenrelated receptor-alpha identified as putative mediators of calf rumen epithelial tissue development and function during weaning. J Dairy Sci. 2014;97:4193-207.

14. Yang B, Chen H, Cao J, He B, Wang S, Luo Y, et al. Transcriptome analysis reveals that alfalfa promotes rumen development through enhanced metabolic processes and calcium transduction in Hu lambs. Front Genet. 2019;10:929.

15. Lin L, Xie F, Sun D, Liu J, Zhu W, Mao S. Ruminal microbiome-host crosstalk stimulates the development of the ruminal epithelium in a lamb model. Microbiome. 2019;7:83.

16. Gorka P, Kowalski ZM, Pietrzak P, Kotunia A, Kiljanczyk R, Flaga J, et al. Effect of sodium butyrate supplementation in milk replacer and starter diet on rumen development in calves. J Physiol Pharmacol. 2009;60(Suppl 3):47-53.

17. Weatherburn M. Phenol-hypochlorite reaction for determination of ammonia. Anal Chem. 1967;39:971-4.

18. Makkar HP, Sharma OP, Dawra RK, Negi SS. Simple determination of microbial protein in rumen liquor. J Dairy Sci. 1982;65:2170-3.

19. Stobo I, Roy J, Gaston HJ. Rumen development in the calf: 1. The effect of diets containing different proportions of concentrates to hay on rumen development. Brit J Nutr. 1966;20:171-88.

20. Malhi M, Gui H, Yao L, Aschenbach JR, Gabel G, Shen Z. Increased papillae growth and enhanced short-chain fatty acid absorption in the rumen of goats are associated with transient increases in cyclin D1 expression after ruminal butyrate infusion. J Dairy Sci. 2013;96:7603-16.

21. Yang H, Wang F, Li F, Ren C, Pang J, Wan Y, et al. Comprehensive analysis of long noncoding RNA and mRNA expression patterns in sheep testicular maturation. Biol Reprod. 2018;99:650-61.

22. Kim D, Langmead B, Salzberg SL. HISAT: a fast spliced aligner with low memory requirements. Nat Methods. 2015;12:357-60.

23. Pertea M, Kim D, Pertea GM, Leek JT, Salzberg SL. Transcript-level expression analysis of RNA-seq experiments with HISAT, StringTie and Ballgown. Nat Protoc. 2016;11:1650-67.

24. Sherman BT, Lempicki RA. Systematic and integrative analysis of large gene lists using DAVID bioinformatics resources. Nat Protoc. 2009;4:44.

25. Xie C, Mao X, Huang J, Ding Y, Wu J, Dong S, et al. KOBAS 2.0: a web server for annotation and identification of enriched pathways and diseases. Nucleic Acids. 2011;39:316-22.

26. Khan MA, Bach A, Weary DM, von Keyserlingk MAG. Invited review: transitioning from milk to solid feed in dairy heifers. J Dairy Sci. 2016;99:885-902.

27. Yang $\mathrm{CM}$. Response of forage fiber degradation by ruminal microorganisms to branched-chain volatile fatty acids, amino acids, and dipeptides. J Dairy Sci. 2002:85:1183-90

28. Grummer RR, Clark JH, Davis CL, Murphy MR. Effect of ruminal ammonianitrogen concentration on protein degradation in situ. J Dairy Sci. 1984;67: 2294-301.

29. Vi RB, McLeod K, Klotz J, Heitmann R. Rumen development, intestinal growth and hepatic metabolism in the pre-and postweaning ruminant. J Dairy Sci. 2004;87:55-65.

30. Malmuthuge N, Liang GX, Guan LL. Regulation of rumen development in neonatal ruminants through microbial metagenomes and host transcriptomes. Genome Biol. 2019;20:172

31. Galfi P, Kutas F, Neogrady S. Immunohistochemical detection of bovine ruminal carbonic anhydrase isoenzyme. Histochemistry. 1982;74:577-84.

32. Naeem A, Drackley JK, Stamey J, Loor JJ. Role of metabolic and cellular proliferation genes in ruminal development in response to enhanced plane of nutrition in neonatal Holstein calves. J Dairy Sci. 2012;95:1807-20.
33. Connor EE, Baldwin RL t, Li CJ, Li RW, Chung H. Gene expression in bovine rumen epithelium during weaning identifies molecular regulators of rumen development and growth. Funct Integr Genomics. 2013;13:133-42.

34. Mitra K, Wunder C, Roysam B, Lin G, Lippincott-Schwartz J. A hyperfused mitochondrial state achieved at G1-S regulates cyclin E buildup and entry into S phase. Proc Natl Acad Sci U S A. 2009;106:11960-5.

35. Liu L, Sun D, Mao S, Zhu W, Liu J. Infusion of sodium butyrate promotes rumen papillae growth and enhances expression of genes related to rumen epithelial VFA uptake and metabolism in neonatal twin lambs. J Anim Sci. 2019;97:909-21.

36. Gui H, Shen Z. Concentrate diet modulation of ruminal genes involved in cell proliferation and apoptosis is related to combined effects of short-chain fatty acid and pH in rumen of goats. J Dairy Sci. 2016;99:6627-38.

37. Mandal S, Freije WA, Guptan P, Banerjee U. Metabolic control of G1-S transition: cyclin $\mathrm{E}$ degradation by $\mathrm{p} 53$-induced activation of the ubiquitinproteasome system. J Cell Biol. 2010;188:473-9.

38. Kabiri Z, Greicius G, Zaribafzadeh H, Hemmerich A, Counter CM, Virshup DM. Wnt signaling suppresses MAPK-driven proliferation of intestinal stem cells. J Clin Invest. 2018;128:3806-12.

39. Hou $Q$, Ye L, Huang $L$, Yu Q. The research progress on intestinal stem cells and its relationship with intestinal microbiota. Front Immunol. 2017:8:599.

40. Wang C, Cao S, Shen Z, Hong Q, Feng J, Peng Y, et al. Effects of dietary tributyrin on intestinal mucosa development, mitochondrial function and AMPK-mTOR pathway in weaned pigs. J Anim Sci Biotechnol. 2019;10:1-10.

41. Wang Y, Zhao H, Shao Y, Liu J, Li J, Xing M. Interplay between elemental imbalance-related PI3K/Akt/mTOR-regulated apoptosis and autophagy in arsenic (III)-induced jejunum toxicity of chicken. Environ Sci Pollut R. 2018; 25:18662-72.

42. Liu J, Bian G, Sun D, Zhu W, Mao S. Starter feeding altered ruminal epithelial bacterial communities and some key immune-related genes' expression before weaning in lambs. J Anim Sci. 2017;95:910-21.

43. Jiao JZ, Zhou CS, Guan LL, McSweeney CS, Tang SX, Wang M, et al. Shifts in host mucosal innate immune function are associated with ruminal microbial succession in supplemental feeding and grazing goats at different ages. Front Microbiol. 2017;8:1655.

44. Yuan ZC, Xu WD, Liu XY, Liu XY, Huang AF, Su LC. Biology of IL-36 signaling and its role in systemic inflammatory diseases. Front Immunol. 2019;10:2532.

45. King CL, Stupi RJ, Craighead N, June CH, Thyphronitis G. CD28 activation promotes Th2 subset differentiation by human CD4+ cells. Eur J Immunol. 1995;25:587-95.

46. Song T, Dong C, Xiong S. Signaling lymphocyte-activation molecule SLAM F1 augments mycobacteria BCG-induced inflammatory response and facilitates bacterial clearance. Int J Med Microbiol. 2015;305:572-80.

47. Xing $S$, Gai $K$, Li X, Shao $P$, Zeng Z, Zhao $X$, et al. Tcf1 and Lef1 are required for the immunosuppressive function of regulatory T cells. J Exp Med. 2019; 216:847-66.

48. Saha S, Qi J, Wang S, Wang M, Li X, Kim Y-G, et al. PGLYRP-2 and Nod2 are both required for peptidoglycan-induced arthritis and local inflammation. Cell Host Microbe. 2009;5:137-50.

49. Tang L, Yang J, Liu W, Tang X, Chen J, Zhao D, et al. Liver sinusoidal endothelial cell lectin, LSECtin, negatively regulates hepatic T-cell immune response. Gastroenterology. 2009;137:1498-508.

50. Wang Y, Shu Y, Xiao Y, Wang Q, Kanekura T, Li Y, et al. Hypomethylation and overexpression of ITGAL (CD11a) in CD4(+) T cells in systemic sclerosis. Clin Epigenetics. 2014;6:25.

51. Zhang W, Sommers CL, Burshtyn DN, Stebbins CC, DeJarnette JB, Trible RP, et al. Essential role of LAT in T cell development. Immunity. 1999;10:323-32.

52. Steele MA, Dionissopoulos L, AlZahal O, Doelman J, McBride BW. Rumen epithelial adaptation to ruminal acidosis in lactating cattle involves the coordinated expression of insulin-like growth factor-binding proteins and a cholesterolgenic enzyme. J Dairy Sci. 2012;95:318-27.

53. Tithof PK, Roberts MP, Guan W, Elgayyar M, Godkin JD. Distinct phospholipase A2 enzymes regulate prostaglandin E2 and F2alpha production by bovine endometrial epithelial cells. Reprod Biol Endocrinol. 2007;5:16.

54. Li X, Wang S, Wang H, Gupta D. Differential expression of peptidoglycan recognition protein 2 in the skin and liver requires different transcription factors. J Biol Chem. 2006;281:20738-48.

55. Lopez-Gomez A, Cano V, Moranta D, Morey P, Garcia Del Portillo F, Bengoechea JA, et al. Host cell kinases, alpha5 and beta1 integrins, and Rac1 signalling on the microtubule cytoskeleton are important for non- 
typable Haemophilus influenzae invasion of respiratory epithelial cells. Microbiology. 2012;158:2384-98.

56. Gadjeva M, Paradis-Bleau C, Priebe GP, Fichorova R, Pier GB. Caveolin-1 modifies the immunity to Pseudomonas aeruginosa. J Immunol. 2010;184: 296-302.

57. Askarian F, Ajayi C, Hanssen A-M, Van Sorge NM, Pettersen I, Diep DB, et al. The interaction between Staphylococcus aureus SdrD and desmoglein 1 is important for adhesion to host cells. Sci Rep. 2016;6:1-11.

58. Yan L, Zhang B, Shen Z. Dietary modulation of the expression of genes involved in short-chain fatty acid absorption in the rumen epithelium is related to short-chain fatty acid concentration and $\mathrm{pH}$ in the rumen of goats. J Dairy Sci. 2014;97:5668-75.

59. Abdoun K, Stumpff F, Martens H. Ammonia and urea transport across the rumen epithelium: a review. Anim Health Res Rev. 2006;7:43-59.

60. Bödeker D, Kemkowski J. Participation of $\mathrm{NH} 4+$ in total ammonia absorption across the rumen epithelium of sheep (Ovis aries). Comp Biochem Phys A. 1996;114:305-10.

61. Stewart GS, Smith CP. Urea nitrogen salvage mechanisms and their relevance to ruminants, non-ruminants and man. Nutr Res Rev. 2005;18:4962.

62. Huntington $G$, Archibeque S. Practical aspects of urea and ammonia metabolism in ruminants. Proc Am Soc Anim Sci. 1999:77:1-11.

63. Remond D, Bernard $L$, Poncet $C$. Free and peptide amino acid net flux across the rumen and the mesenteric- and portal-drained viscera of sheep. J Anim Sci. 2000;78:1960-72.

64. Quigley JD 3rd, Schwab CG, Hylton WE. Development of rumen function in calves: nature of protein reaching the abomasum. J Dairy Sci. 1985;68:694702.

65. Kirat D, Sallam KI, Kato S. Expression and cellular localization of monocarboxylate transporters (MCT2, MCT7, and MCT8) along the cattle gastrointestinal tract. Cell Tissue Res. 2013;352:585-98.

66. Kong RS, Liang G, Chen Y, Stothard P, Guan le L. Transcriptome profiling of the rumen epithelium of beef cattle differing in residual feed intake. BMC Genomics. 2016;17:592

67. Kelly J, Vaage A, Milligan L, McBride B. In vitro ouabain-sensitive respiration and protein synthesis in rumen epithelial papillae of Hereford steers fed either timothy hay or timothy hay supplemented with cracked corn once daily. J Anim Sci. 1995;73:3775-84.

68. Baldwin RL t, Connor EE. Rumen function and development. Vet Clin North Am Food Anim Pract. 2017;33:427-39.

69. Early R, McBride B, Ball R. Growth and metabolism in somatotropin-treated steers: III. Protein synthesis and tissue energy expenditures. J Anim Sci. 1990; 68:4153-66.

70. Bergen WG. Free amino acids in blood of ruminants - physiological and nutritional regulation. J Anim Sci. 1979;49:1577-89.

Ready to submit your research? Choose BMC and benefit from:

- fast, convenient online submission

- thorough peer review by experienced researchers in your field

- rapid publication on acceptance

- support for research data, including large and complex data types

- gold Open Access which fosters wider collaboration and increased citations

- maximum visibility for your research: over $100 \mathrm{M}$ website views per year

At BMC, research is always in progress.

Learn more biomedcentral.com/submissions 